\title{
Airway ciliary dysfunction: Association with adverse postoperative outcomes in nonheterotaxy congenital heart disease patients
}

\author{
Eileen Stewart, MD, ${ }^{\mathrm{a}}$ Phillip S. Adams, DO,${ }^{\mathrm{b}}$ Xin Tian, $\mathrm{PhD},{ }^{\mathrm{e}}$ Omar Khalifa, MD, \\ Peter Wearden, MD, PhD, ${ }^{d}$ Maliha Zahid, MD, PhD,${ }^{c}$ and Cecilia W. Lo, $\mathrm{PhD}^{\mathrm{c}}$
}

\section{ABSTRACT}

Objective: Heterotaxy (HTX) congenital heart disease (CHD) patients with ciliary dysfunction (CD) have been shown to have increased postoperative respiratory morbidity. We hypothesized that non-HTX CHD infants with CD also will have increased postoperative morbidity, particularly respiratory complications.

Methods: Sixty-three infants with non-HTX CHD undergoing cardiac surgery were enrolled. Tests commonly used to assess for $\mathrm{CD}$, nasal nitric oxide (nNO) measurements and nasal epithelial ciliary motion (CM) assessment, were obtained. Baseline characteristics and postoperative outcomes were collected and analyzed.

Results: Non-HTX CHD infants exhibited a high prevalence of abnormal CM $(32 \%)$ and low nNO (39\%). This finding was not correlated with demographics or surgical complexity. Infants with abnormal CM had increased odds of requiring noninvasive positive pressure ventilation (odds ratio [OR], 6.5; 95\% confidence interval $[\mathrm{CI}], 1.5-29.4 ; P=.016)$ and respiratory medication use (OR, 4.4; $95 \% \mathrm{CI}, 1.5-13.3 ; P=.01)$. In contrast, infants with low nNO showed evidence of abnormal pre- and postoperative systolic function $(40 \%$ vs $4 \% ; P=.004$, and $34 \%$ vs $13 \% ; P=.056$, respectively) and had greater odds of acquiring infections (OR, 4.9; 95\% CI, 1.4-17; $P=.014)$.

Conclusions: Non-HTX CHD infants with abnormal CM showed increased postoperative morbidity associated with poor respiratory outcomes. In contrast, low nNO correlated with reduced hemodynamic function. These findings suggest screening for abnormal CM may allow perioperative interventions to reduce pulmonary morbidities. Whether low nNO may prognosticate poor hemodynamic function warrants further investigation. ( $\mathrm{J}$ Thorac Cardiovasc Surg 2018;155:755-63)

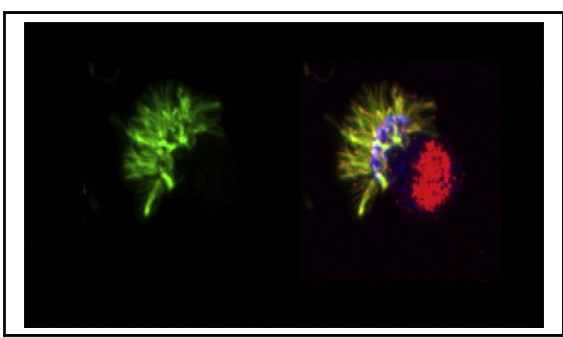

Ciliary axoneme of a human nasal epithelia cell visualized by immunostaining.

Central Message

Airway ciliary dysfunction is associated with increased pulmonary morbidity after congenital cardiac surgery in infants with nonheterotaxy congenital heart disease.

\section{Perspective}

Current evidence suggests airway ciliary dysfunction in congenital heart disease (CHD) patients with heterotaxy is associated with increased postoperative pulmonary morbidity. Here, analysis of patients with a broad spectrum of nonheterotaxy CHD yielded similar findings. These results suggests that preoperative screening for ciliary dysfunction may allow therapeutic interventions to improve outcomes for at-risk CHD patients.

See Editorial Commentary page 764.

\footnotetext{
From the ${ }^{\mathrm{a}}$ Division of Pediatric Cardiology, Department of Pediatrics, ${ }^{\mathrm{b}}$ Division of Pediatric Anesthesiology, Department of Anesthesiology, ${ }^{\mathrm{c}}$ Department of Developmental Biology, and ${ }^{\mathrm{d}}$ Division of Pediatric Cardiothoracic Surgery, Department of Surgery, University of Pittsburgh School of Medicine, Pittsburgh, Pa; and ${ }^{\mathrm{C}} \mathrm{Of}-$ fice of Biostatistics Research, National Heart, Lung, and Blood Institute, Bethesda, Md.

This work was supported by the Pennsylvania Department of Health, and the Department of Defense grant W81XWH-15-1-0649; Sang C. Park Fellow Research Award (16060). P. S. Adams is supported in part by a training grant from the National Institutes of Health (T32GM075770)

Received for publication Feb 12, 2017; revisions received Aug 30, 2017; accepted for publication Sept 10, 2017; available ahead of print Oct 19, 2017

Address for reprints: Cecilia W. Lo, PhD, Department of Developmental Biology, University of Pittsburgh School of Medicine, 530 45th St, Pittsburgh, PA 15201 (E-mail: ce136@pitt.edu).

$0022-5223 / \$ 36.00$

Copyright (C) 2017 by The American Association for Thoracic Surgery

https://doi.org/10.1016/j.jtcvs.2017.09.050
}

The survival of patients with critical congenital heart disease (CHD) has improved greatly with surgical advances and improvements in critical care. However, postoperative morbidity remains a significant problem, with respiratory complications being a substantial burden. A mechanistic link between CHD and the disturbance of airway clearance

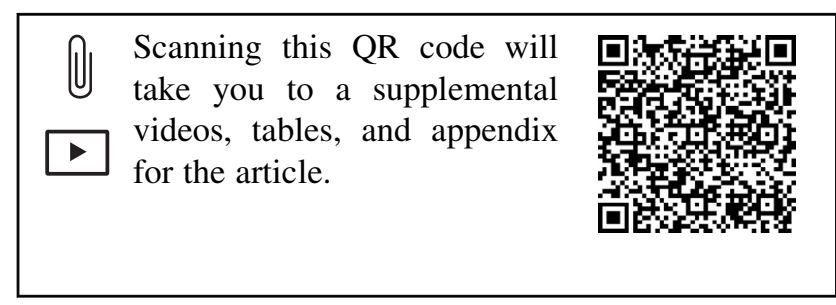




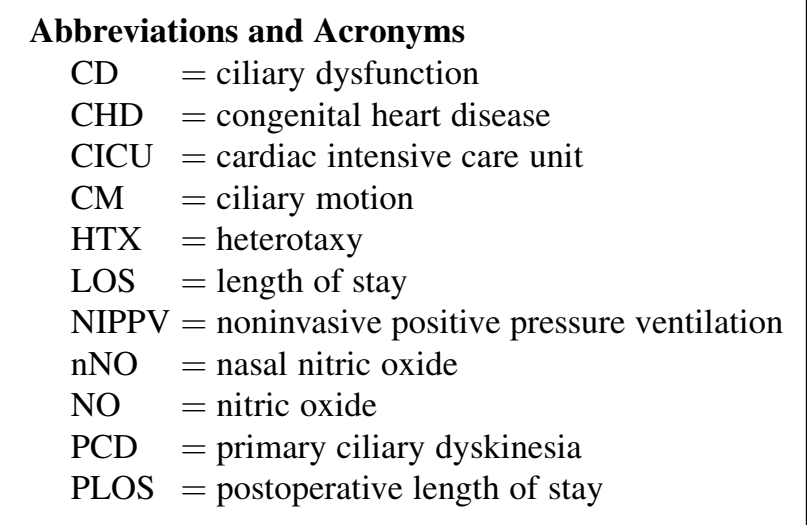

was suggested with the recent realization that motile cilia are required for both airway mucociliary clearance and embryonic development of visceral organ asymmetry, including the cardiovascular system. ${ }^{1-4}$ Indeed, previous studies have shown CHD patients with heterotaxy (HTX), a birth defect involving randomized left-right patterning, have a high prevalence of motile ciliary dysfunction (CD), with those exhibiting CD suffering increased postoperative morbidity. ${ }^{5-7}$

CD in HTX CHD patients was identified by measuring nasal nitric oxide (nNO) and obtaining nasal epithelial scrapes for ciliary videomicroscopy assessment, 2 tests commonly used to evaluate for primary ciliary dyskinesia (PCD), a sinopulmonary disease associated with very low nNO and immotile or dyskinetic airway ciliary motion (CM). ${ }^{8}$ With these same tests, a study was conducted on outpatients with a broad spectrum of both HTX and nonHTX CHD, revealing a similarly high prevalence of CD (combination of both abnormal CM and low nNO in 33\% of HTX CHD and $17 \%$ of non-HTX CHD). ${ }^{9} \mathrm{CD}$ in these patients was associated with increased sinopulmonary symptoms, with ciliary function status shown to be more important than HTX status for determining the risk of manifesting sinopulmonary symptoms. ${ }^{9}$

In this current study, we investigated the hypothesis that non-HTX CHD patients with CD have increased postoperative morbidity and more respiratory complications. With previous evidence that $\mathrm{CHD}$ patients with $\mathrm{CD}$ could have abnormal CM with normal nNO or low nNO with normal $\mathrm{CM},{ }^{9}$ we further examined whether abnormal $\mathrm{CM}$ versus low $\mathrm{nNO}$ posed different risks for postoperative morbidity.

\section{METHODS}

\section{Patient Recruitment}

Patients younger than 1 year of age with non-HTX CHD were prospectively enrolled from 2010 to 2014 at Children's Hospital of Pittsburgh of the University of Pittsburgh Medical Center (Pittsburgh, Pa). This age group was chosen to minimize heterogeneity in the study population. This infant cohort is a subset of a larger database containing patients of all ages with all types of CHD. Informed consent was obtained from parents or guardians of patients. The study protocol was approved and performed in accordance with the Institutional Review Board of the University of Pittsburgh (PRO09090021; approved December 14, 2009, renewed September 1, 2016).

\section{Inclusion Criteria}

CHD patients recruited in this study comprised those with malformations of the heart and/or great arteries without laterality defects. All nonHTX CHD patients who had at least 1 cardiac surgery before 1 year of age were eligible for inclusion in the study. Patients hospitalized greater than 3 months before surgical repair or those with iatrogenic airway injury were excluded from the study. Minor surgical encounters including thrombectomy, isolated vessel reconstruction, sternal closure, and extracorporeal membrane oxygenation cannulation and decannulation were excluded from analysis as independent surgical events.

\section{nNO Measurement}

nNO measurements were obtained preoperatively with a CLD $88 \mathrm{sp}$ (Eco Physics AG; Ann Arbor, Mich) nitric oxide (NO) analyzer according to established protocols with the tidal breath sampling technique. ${ }^{10,11}$ Infants were classified as having normal or low nNO based on the published prediction interval of normative infant $\mathrm{nNO}$ values. ${ }^{12}$

\section{Analysis}

Nasal epithelial tissue was obtained using rhino-probe curettage of the inferior nasal turbinate during the preoperative period. CM was examined using high-speed videomicroscopy via methods previously described. ${ }^{6,9}$ To rule out $\mathrm{CM}$ defects secondary to environmental insults like infection or allergy, nasal epithelial tissue was placed into culture after videomicroscopy for expansive growth and reciliation as described previously. ${ }^{9}$ The reciliated tissue was examined by videomicroscopy to assess whether CM was normal or abnormal (Appendix 1 and Videos 1 and 2). In cases in which the initial scrape and reciliation results were discordant, the CM status was determined from the reciliation data.

\section{Outcome Data Collection}

We collected data from each major surgical encounter a patient experienced over the study period. All clinical staff were blinded to the patients'

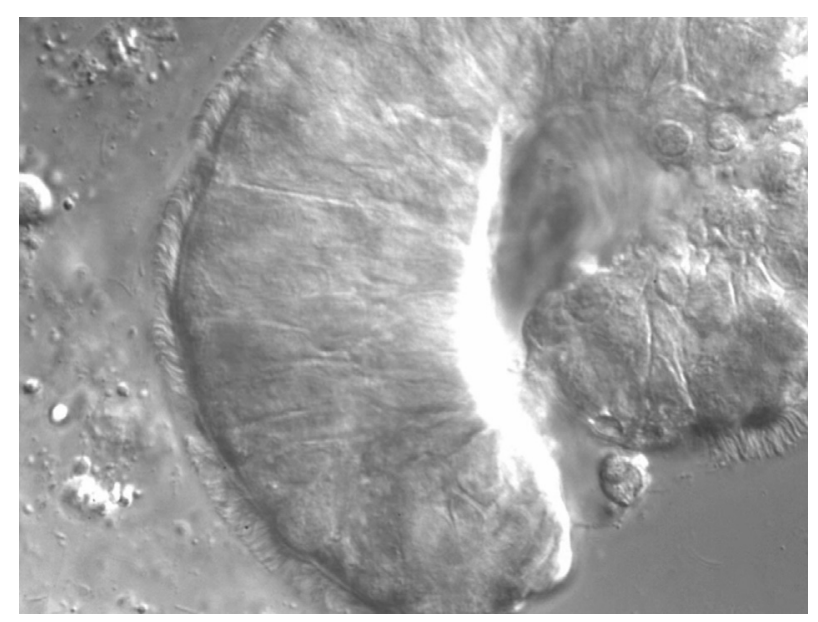

VIDEO 1. Nasal epithelial cells from a patient with normal ciliary motion. These nasal epithelial cells bear abundant cilia with long, synchronized, coordinated strokes. Note the ability of the beating cilia to move pericellular debris. Video available at: http://www.jtcvsonline.org/article/S00225223(17)31968-2/fulltext. 


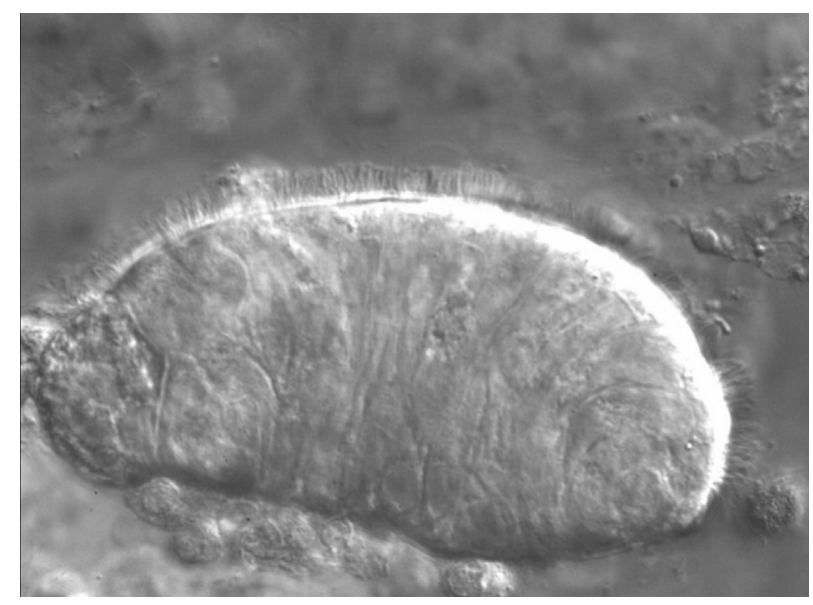

VIDEO 2. Nasal epithelial cells from a patient with abnormal ciliary motion. These nasal epithelial cells have stiff, dyskinetic, wavy cilia with uncoordinated strokes. Video available at: http://www.jtcvsonline.org/article/ S0022-5223(17)31968-2/fulltext.

$\mathrm{CM}$ and $\mathrm{nNO}$ assessments. Detailed demographic, surgical, and postoperative outcome data were abstracted from the electronic medical record using patient discharge summaries, progress notes, operative reports, and daily flowsheets. Basic demographic data were collected, including age at nNO and CM sampling, sex, race, and gestational age. Medical history and preoperative data were gathered including an anatomic description of CHD, genetic evaluation (Appendix 1), comorbidities, age at surgery, preoperative weight, and preoperative systemic systolic ventricular function. Surgical mortality and risk adjustment scores were collected, including the Society of Thoracic Surgeons and European Association for Cardio-Thoracic Surgery Congenital Heart Surgery Database categories, Aristotle Basic Complexity score (Aristotle), and Risk Adjustment in Congenital Heart Surgery score. ${ }^{13-15}$

Length of stay (LOS) parameters collected included postoperative length of stay (PLOS), initial cardiac intensive care unit (CICU) LOS, and total CICU LOS, which included additional time spent in CICU due to readmission after initial transfer to the step-down unit. Ventilation parameters collected included mechanical ventilation days, noninvasive positive pressure ventilation (NIPPV) days, and supportive ventilation days, which included high-flow nasal cannula and nasal cannula. Duration of postoperative medication requirements were recorded after each major surgical encounter.

Data regarding postoperative complications were gathered, including reintubations, development of pleural effusions and/or pneumothoraces, necrotizing enterocolitis, and infections. Failed extubation was defined as a patient being reintubated less than 24 hours after extubation. Pleural effusions were only counted if they required chest tube drainage. Intrinsic airway disease was noted for patients with endoscopic evidence of external or internal airway compression or vocal cord dysfunction. Pneumothorax was defined as clinical symptoms with radiographic evidence of air in the pleural space. Diaphragm paresis was noted for patients with sonographic or fluoroscopic evidence of paresis. Qualitative systemic ventricular function was abstracted from transthoracic echocardiography assessments by pediatric cardiologists who were blinded to all aspects of the study. Viral infection was defined as presence of clinical symptoms and positive nasal viral panel. Bacterial infection was defined as presence of clinical symptoms and positive blood culture and excluded pneumonia and tracheitis. Fungal infection was defined as presence of clinical symptoms and positive fungal culture. Pneumonia (bacterial) was defined as clinical symptoms, the presence of infiltrate on chest radiograph, and infectious disease recommendation to treat with antimicrobials for bacterial pneumonia. Tracheitis was defined as clinical symptoms and positive tracheal culture.

\section{Statistical Analysis}

Summary statistics such as proportion and median with interquartile range were used to describe patient characteristics and their postoperative outcomes. For patient characteristics, the $\chi^{2}$ test was used to compare categorical variables and the Fisher exact test was applied when appropriate, and Wilcoxon rank-sum test was used to compare continuous variables between subgroups. For baseline surgical characteristics and postoperative outcomes, mixed-effects models were applied to adjust for the intrasubject correlation among multiple surgical events of individual patients. As the postoperative continuous outcomes were right-skewed, the linear mixed models for repeated measures were used to analyze the effect of $\mathrm{CM}$ and $\mathrm{nNO}$ on the log-transformed continuous outcomes that were approximately normal after transformation. The generalized linear mixed models for repeated measures were used for assess the differences in the categorical outcomes between the abnormal and normal $\mathrm{CM}$ or nNO subgroups. Multivariate analysis of adverse postoperative outcomes based on generalized linear mixed models was performed to examine the effect of $\mathrm{CM}$ or $\mathrm{nNO}$, controlling for baseline surgical characteristics (age, weight, surgical severity, ventricular function, and single-ventricle status). All tests were 2sided, and a $P$ value $\leq .01$ was considered statistically significant. A more conservative significance level of .01 was used to adjust for multiple comparisons. Statistical analyses were performed with SAS 9.4 (SAS Institute Inc, Cary, NC) and STATA 12.1 (STATA Corp, College Station, Tex).

\section{RESULTS}

\section{Baseline Demographics}

We recruited 63 infants with a broad spectrum of critical non-HTX CHD (Figure 1 and Table E1). Two patients had 1 of 2 surgical encounters excluded: One for hospitalization $>3$ months before surgical repair and the other for iatrogenic tracheal injury. During the study period, the survival rate was $99 \%$, with only 1 patient death reported in the immediate postoperative period, precluding analysis of postoperative mortality.

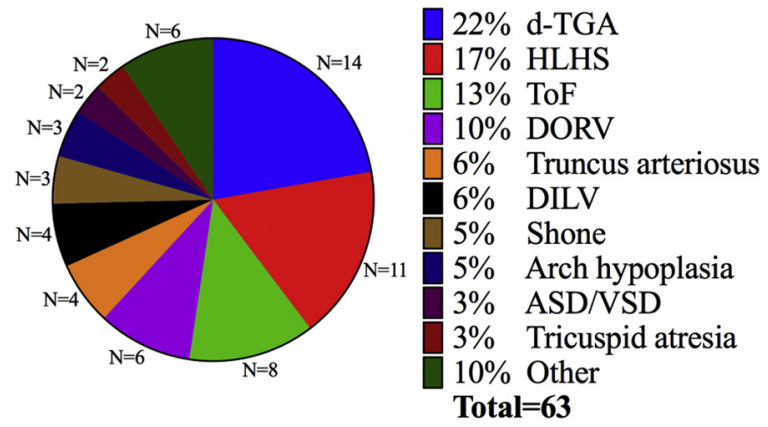

FIGURE 1. Spectrum of CHD in study participants. The distribution of non-HTX CHD observed in study participants is summarized in this pie chart. "Other" category includes 1 patient each with pulmonary atresia/ intact ventricular septum, isolated infradiaphragmatic total anomalous pulmonary venous return, double-outlet left ventricle, critical aortic stenosis, complete atrioventricular septal defect, and anomalous left coronary artery from the pulmonary artery. $d-T G A, \mathrm{~d}$-Transposition of the great arteries; $H L H S$, hypoplastic left heart syndrome; ToF, tetralogy of Fallot; DORV, double-outlet right ventricle; $D I L V$, double-inlet left ventricle; $A S D / V S D$, atrial septal defect/ventricular septal defect. 

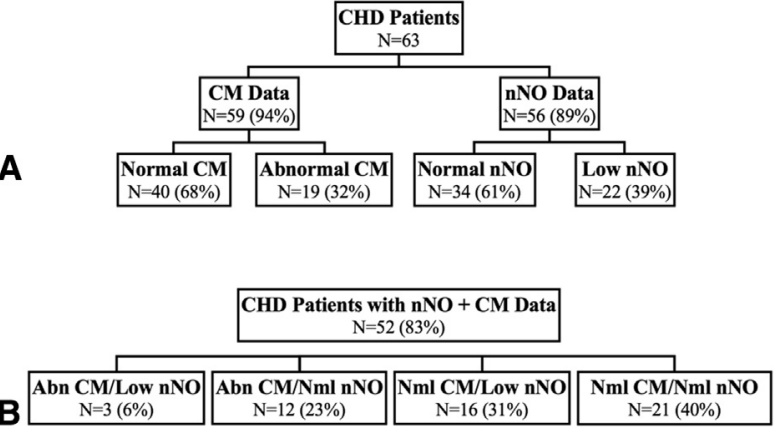

FIGURE 2. Summary of ciliary motion and nasal nitric oxide findings in non-HTX CHD patients. A, Distribution of normal/abnormal CM and nNO in all non-HTX CHD patients. B, Distribution of normal/abnormal CM and $\mathrm{nNO}$ in non-HTX CHD patients with both $\mathrm{CM}$ and $\mathrm{nNO}$ data. CHD, Congenital heart disease; $C M$, ciliary motion; $n N O$, nasal nitric oxide; $\mathrm{Abn}$, abnormal; $\mathrm{Nml}$, normal.

The most common cardiac abnormalities in study participants were d-transposition of the great arteries (14 patients) and hypoplastic left heart syndrome (11 patients). Thirtysix $(57 \%)$ patients exhibited conotruncal defects (Table E2). The majority of the patients were male $(67 \%)$, born at full term (97\%), and white (87\%), with the remainder being African American (6\%), Hispanic (3\%), Arab (2\%), and Asian (2\%) (Table E2). Genetic evaluation, carried out by microarray analysis as the standard of care (Appendix 1), was abnormal in $24 \%$ of study participants (Table E2). Detailed information regarding anatomic subtypes of CHD, comorbidities of each patient, and genetic abnormalities is provided in Table E1.

\section{Baseline Demographics Stratified by CM and nNO Status}

Nasal scrapes were obtained in $59(94 \%)$ patients for CM analysis, and nNO measurements were performed in 56 (89\%) (Figure 2, A, and Table E3). Abnormal CM was observed in $32 \%$ of the patients. Low $\mathrm{nNO}$ was observed in $39 \%$ of the patients. For patients $(\mathrm{N}=52)$ with both $\mathrm{CM}$ and nNO assessments, $6 \%$ had both abnormal $\mathrm{CM}$ and low nNO (Figure 2, B, and Table E3). There was no significant difference in recruitment age or prematurity, sex, race, or presence of an abnormal genetic evaluation in patients with abnormal versus normal $\mathrm{CM}$ and low versus normal nNO (Table E2). Patients with low nNO were recruited at an older age than patients with normal $\mathrm{nNO}(24$ [6-53] days vs 5 [3-21] days, respectively; $P=.038$ ). Conotruncal defects were significantly more common in patients with abnormal CM $(84 \%$ vs $48 \%, P=.01)$.

TABLE 1. Baseline surgical parameters in CHD patients by ciliary motion and nasal nitric oxide

\begin{tabular}{|c|c|c|c|c|c|}
\hline & \multirow[b]{2}{*}{ All surgical events $(n=95)$} & \multicolumn{2}{|c|}{ Events with $\mathrm{CM}$ data $(\mathrm{n}=91)$} & \multicolumn{2}{|c|}{ Events with nNO data $(n=83)$} \\
\hline & & $\overline{\text { Normal }(n=58)}$ & Abnormal $(n=33)$ & $\overline{\text { Normal }(n=48)}$ & Low $(n=35)$ \\
\hline \multirow[t]{2}{*}{ Age at surgery, $d$} & $14(7-91)$ & $11(6-84)$ & $30(9-127)$ & $9(7-92)$ & $30(8-91)$ \\
\hline & & \multicolumn{2}{|c|}{$P=.060$} & \multicolumn{2}{|c|}{$P=.23$} \\
\hline \multirow[t]{2}{*}{ Preoperative weight, $\mathrm{kg}$} & $3.7(3.1-5.0)$ & $3.4(3.1-4.7)$ & $4.3(3.2-6.1)$ & $3.7(3.1-4.9)$ & $3.5(3.1-5.1)$ \\
\hline & & \multicolumn{2}{|c|}{$P=.054$} & \multicolumn{2}{|c|}{$P=.99$} \\
\hline \multirow[t]{2}{*}{ STS-EACTS category* } & $3(2-4)$ & $3(2-4)$ & $3(2-4)$ & $3(2-4)$ & $3(2-4)$ \\
\hline & & \multicolumn{2}{|c|}{$P=.65$} & \multicolumn{2}{|c|}{$P=.47$} \\
\hline \multirow[t]{2}{*}{ Abn PreOp Sys Fxn, n (\%) } & $21(22)$ & $13(22)$ & $7(21)$ & $2(4 \%)$ & $14(40)$ \\
\hline & & \multicolumn{2}{|c|}{$P=.64$} & \multicolumn{2}{|c|}{$P=.004$} \\
\hline \multirow[t]{2}{*}{ Single-ventricle palliation, $\mathrm{n}(\%)$} & $40(42)$ & $30(52)$ & $10(30)$ & $14(29)$ & $20(57)$ \\
\hline & & \multicolumn{2}{|c|}{$P=.15$} & \multicolumn{2}{|c|}{$P=.061$} \\
\hline \multirow[t]{2}{*}{ Surgeon $1, \mathrm{n}(\%)$} & $68(72)$ & $41(71)$ & $24(73)$ & $34(71)$ & $26(74)$ \\
\hline & & \multicolumn{2}{|c|}{$P=.87$} & \multicolumn{2}{|c|}{$P=.51$} \\
\hline \multirow[t]{2}{*}{ CPB time, min } & $88(62-115)$ & $89(66-112)$ & $89(55-134)$ & $86(57-120)$ & $91(65-108)$ \\
\hline & & \multicolumn{2}{|c|}{$P=.32$} & \multicolumn{2}{|c|}{$P=.96$} \\
\hline \multirow[t]{2}{*}{$\mathrm{XC}$ time, $\min$} & $27(0-53)$ & $23(0-44)$ & $44(0-54)$ & $30(0.8-55)$ & $26(0-46)$ \\
\hline & & \multicolumn{2}{|c|}{$P=.36$} & \multicolumn{2}{|c|}{$P=.54$} \\
\hline \multirow[t]{2}{*}{ DHCA, n (\%) } & $28(30)$ & $21(36)$ & $7(21)$ & $14(29)$ & $11(31)$ \\
\hline & & \multicolumn{2}{|c|}{$P=.15$} & \multicolumn{2}{|c|}{$P=.83$} \\
\hline
\end{tabular}

Data are median (interquartile range) or $\mathrm{n}(\%) . P$ values obtained from the linear mixed models and generalized linear mixed model for continuous and categorical variables, respectively. CM, Ciliary motion; $n N O$, nasal nitric oxide; STS-EACTS, Society of Thoracic Surgeons-European Association for Cardio-Thoracic Surgery; Abn PreOp Sys Fxn, abnormal preoperative systolic ventricular function of systemic ventricle; $C P B$, cardiopulmonary bypass; $X C$, aortic crossclamp; $D H C A$, deep hypothermic circulatory arrest. *Empirically based mortality stratification, categories of $1-5$ with greater numbers implying greater mortality risk, based on of the STS-EACTS Congenital Heart Surgery Database. 
TABLE 2. Association between abnormal CM and postoperative outcomes

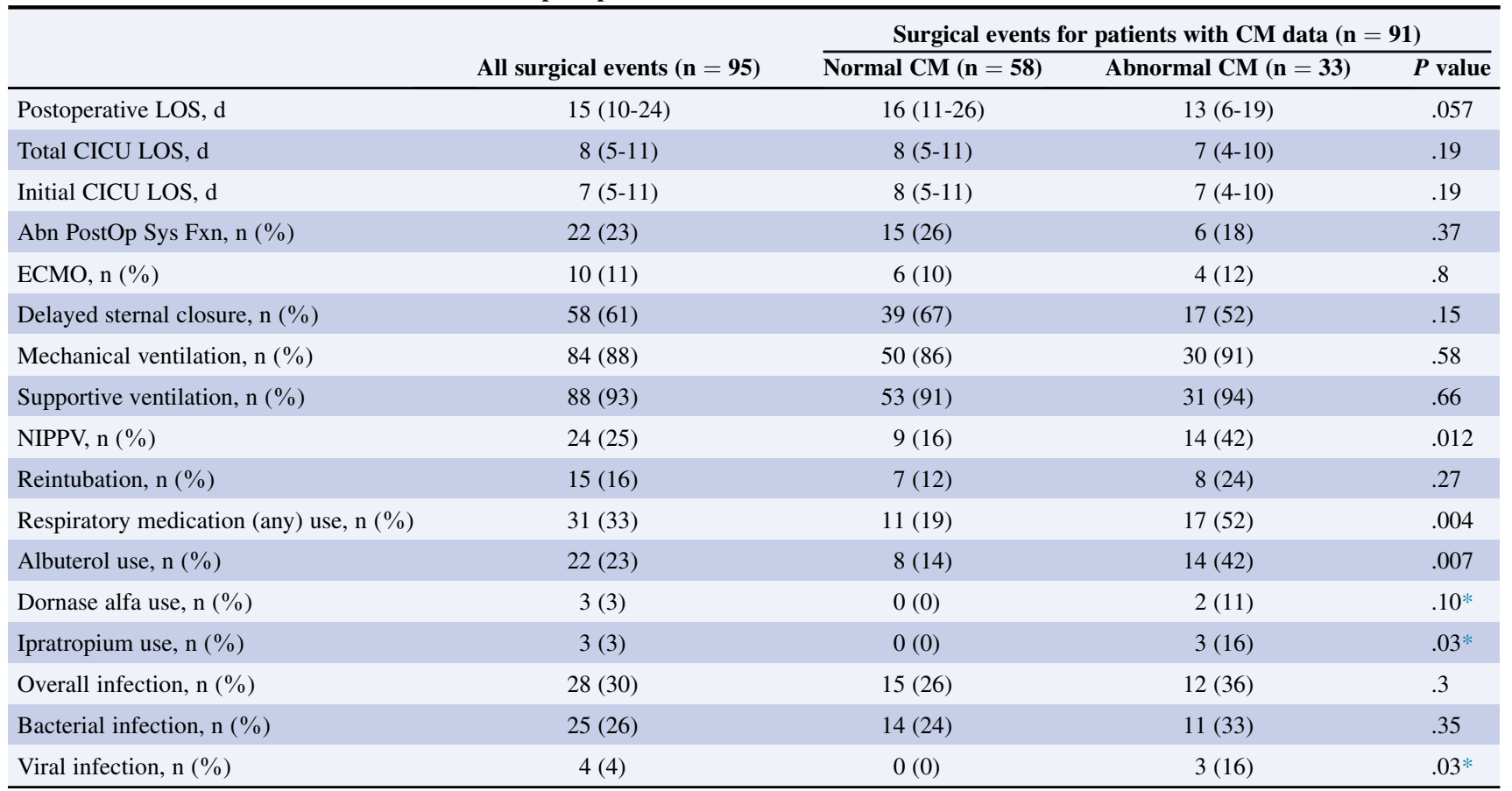

Data are median (interquartile range) or $\mathrm{n}(\%) . P$ values obtained by from the linear mixed models and generalized linear mixed model for continuous and categorical variables, respectively. $C M$, Ciliary motion; $L O S$, length of stay; $C I C U$, cardiac intensive care unit; Abn Post $O p$ Sys Fxn, abnormal postoperative systolic ventricular function of systemic ventricle; $E C M O$, extracorporeal membrane oxygenation; $N I P P V$, noninvasive positive pressure ventilation. $* P$ value by the Fisher exact test for testing whether the percentages are difference between the normal CM $(\mathrm{n}=40)$ and abnormal CM $(\mathrm{n}=19)$ patients

\section{Preoperative Surgical Data}

The 63 CHD infants recruited into this study collectively had 95 surgical encounters available for analysis. The median age of recruitment was 10 [3-29] days (Table E2). The median age at surgery was 14 [7-91] days (Table 1). Single-ventricle palliation was performed in $40(42 \%)$ patient encounters, with surgeon 1 (of 2) performing 68 $(72 \%)$ of the surgical cases.

Of the 95 surgical events, $36 \%$ occurred in patients with abnormal $\mathrm{CM}, 42 \%$ in patients with low nNO, and $8 \%$ in patients with both abnormal $\mathrm{CM}$ and nNO. There was no difference in preoperative weight, Society of Thoracic Surgeons-European Association for Cardio-Thoracic Surgery category, Risk Adjustment in Congenital Heart Surgery or Aristotle scores, surgeon, median cardiopulmonary bypass time, crossclamp time, or deep hypothermic circulatory arrest time among patients stratified either by $\mathrm{CM}$ or $\mathrm{nNO}$ status (Table 1). There was a trend toward younger age at surgery in patients with normal CM (11 [6-84] days vs 30 [9-127] days; $P=.06$ ). No difference was found in preoperative systolic function by CM status. However, abnormal systolic function was significantly associated with low $\mathrm{nNO}$ ( $40 \%$ vs $4 \% ; P=.004)$ (Table 1$)$.

\section{Postoperative Outcome Assessments}

Our patient cohort had a median PLOS of 15 [10-24] days (Table 2). The median total CICU LOS was 8 [5-11] days, and initial CICU LOS was 7 [5-11] days. In patients with low nNO, initial CICU LOS (10 [5-12] days vs 7 [4-8] days; $P=.042)$ and total CICU LOS (10 [5-12] days vs 7 [4-9] days; $P=.041$ ) were longer (Table 3). These low nNO patients also had a greater prevalence of decreased postoperative systolic function ( $34 \%$ vs $13 \% ; P=.056)$. The decreased systolic function in the low nNO patients persisted in 9 of 16 patients up to the time of hospital discharge. Low nNO also was correlated with an increase in number of days treated with milrinone (6 [4-8] days vs 4 [3-6] days; $P=.021$ ), dexmedetomidine (6 [3-8] days vs 3 [2-6] days; $P=.002$ ), and nicardipine requirement (34\% vs $6 \% ; P=.034$ ) (Table 3 ). All other postoperative medications used, including inhaled NO, were not different among patients with normal or low nNO (Table E4).

Patients with abnormal CM showed no difference in total or initial CICU LOS or postoperative systolic function. Neither abnormal CM nor low nNO was correlated with differences in PLOS, days of extracorporeal membrane oxygenation, or CICU readmission (Tables 2 and 3). We also found no correlation between the incidence of necrotizing enterocolitis or use of a nasogastric tube for nutrition at hospital discharge stratified by $\mathrm{CM}$ or nNO status (Table E5). Patients exhibiting both abnormal $\mathrm{CM}$ and low $\mathrm{nNO}$ comprised only 3 patients and 6 surgical events, precluding any meaningful analysis of outcome parameters in this small subset of patients. 
TABLE 3. Association between low nNO and postoperative outcomes

\begin{tabular}{|c|c|c|c|c|}
\hline & \multirow[b]{2}{*}{ All surgical events $(n=95)$} & \multicolumn{3}{|c|}{ Surgical events for patients with nNO data $(n=83)$} \\
\hline & & Normal nNO $(n=48)$ & Low nNO $(n=35)$ & $P$ value \\
\hline Postoperative LOS, d & $15(10-24)$ & $15(10-20)$ & $18(10-29)$ & .28 \\
\hline Total CICU LOS, d & $8(5-11)$ & $7(4-9)$ & $10(5-12)$ & .041 \\
\hline Initial CICU LOS, d & $7(5-11)$ & $7(4-8)$ & $10(5-12)$ & .042 \\
\hline Abn PostOp Sys Fxn, n (\%) & $22(23)$ & $6(13)$ & $12(34)$ & .056 \\
\hline ECMO, n $(\%)$ & $10(11)$ & $6(13)$ & $3(9)$ & .58 \\
\hline Delayed sternal closure, n (\%) & $58(61)$ & $28(58)$ & $23(66)$ & .50 \\
\hline Mechanical ventilation, $\mathrm{n}(\%)$ & $84(88)$ & $42(88)$ & $31(89)$ & .91 \\
\hline Supportive ventilation, n (\%) & $88(93)$ & $46(96)$ & $32(91)$ & .42 \\
\hline NIPPV, n (\%) & $24(25)$ & $11(23)$ & $8(23)$ & .92 \\
\hline Reintubation, $\mathrm{n}(\%)$ & $15(16)$ & $6(13)$ & $7(20)$ & .39 \\
\hline Respiratory medication (any) use, $\mathrm{n}(\%)$ & $31(33)$ & $13(27)$ & $12(34)$ & .50 \\
\hline Dexmedetomidine, $\mathrm{d}$ & $4(2-7)$ & $3(2-6)$ & $6(3-8)$ & .002 \\
\hline Fentanyl, d & $3(2-5)$ & $3(2-5)$ & $4(3-6)$ & .098 \\
\hline Milrinone, $\mathrm{d}$ & $5(3-7)$ & $4(3-6)$ & $6(4-8)$ & .021 \\
\hline Nicardipine use, n (\%) & $17(18)$ & $3(6)$ & $12(34)$ & .034 \\
\hline Overall infection, $\mathrm{n}(\%)$ & $28(30)$ & $8(17)$ & $16(46)$ & .01 \\
\hline Bacterial infection, $\mathrm{n}(\%)$ & $25(26)$ & $8(17)$ & $13(37)$ & .048 \\
\hline Viral infection, $\mathrm{n}(\%)$ & $4(4)$ & $1(2)$ & $1(3)$ & .83 \\
\hline
\end{tabular}

Data are median (interquartile range) or $\mathrm{n}(\%) . P$ values were obtained from the linear mixed models and generalized linear mixed model for continuous and categorical variables, respectively. $n N O$, Nasal nitric oxide; $L O S$, length of stay; $C I C U$, cardiac intensive care unit; Abn PostOp Sys Fxn, abnormal postoperative systolic ventricular function of systemic ventricle; $E C M O$, extracorporeal membrane oxygenation; $N I P P V$, noninvasive positive pressure ventilation.

\section{Postoperative Respiratory Outcome Assessments}

There was no difference observed for the requirement of mechanical ventilation or other supportive ventilation, including high-flow nasal cannula and nasal cannula among patients with abnormal $\mathrm{CM}$, but the requirement of NIPPV was greater $(42 \%$ vs $16 \% ; P=.012)$ (Table 2$)$. A significantly greater use of respiratory medications, inclusive of inhaled $\beta$-agonists, inhaled corticosteroids, mucolytics, and lung surfactant, was observed in patients with abnormal CM $(52 \%$ vs $19 \% ; P=.004)$ (Table 2). Multivariate analysis also indicated that the odds of requiring NIPPV, receiving $\beta$-agonist therapy, and receiving any type of respiratory medication were significantly greater in patients with abnormal CM compared with those for infants with normal CM (Table 4). In contrast, none of these parameters were significantly changed in patients with low nNO. Mechanical ventilation days, NIPPV, duration of supportive ventilation, and respiratory medication use were not affected by low nNO (Table 3). Neither abnormal CM nor low nNO correlated with changes in the rate of reintubation, failed extubation, pneumothorax, incidence of diaphragm paralysis or tracheostomy, presence of intrinsic airway disease, presence of effusion, number of chest tube days, or the amount of chest tube drainage (Tables 2 and 3; Table E5).

\section{Postoperative Infection Outcomes}

A greater proportion of patients with abnormal CM had respiratory viral infections ( 3 of 19 patients [ $16 \%$ ] vs $0 \%$; $P=.03$ ) (Table 2), but no difference was observed for bacterial infection or combined infection incidence (bacterial, viral, fungal infections, pneumonia, tracheitis) (Table 2 and Table E5). In contrast, patients with low nNO had an increased incidence of bacterial infections $(37 \%$ vs

TABLE 4. Multivariate analysis of $\mathrm{CM}$ and $\mathrm{nNO}$ for adverse postoperative outcomes

\begin{tabular}{lcc}
\hline \multicolumn{1}{c}{ Outcomes } & $\begin{array}{c}\text { Adjusted odds ratio } \\
(\mathbf{9 5} \% \mathbf{C I})\end{array}$ & $\boldsymbol{P}$ value \\
\hline Abnormal vs normal CM & & \\
$\quad$ NIPPV & $6.53(1.47-29.4)$ & .016 \\
$\quad \beta$-Agonist use & $5.78(1.60-20.8)$ & .009 \\
Respiratory medication use & $4.42(1.47-13.3)$ & .01 \\
Low vs normal nNO & & \\
Overall infection & $4.90(1.42-17.0)$ & .014 \\
Bacterial infection & $2.95(0.82-10.6)$ & .094 \\
\hline
\end{tabular}

For each postoperative outcome, a generalized linear mixed model with the logit-link was carried out to estimate the adjusted odds ratio for the $\mathrm{CM}$ or nNO group, controlling for the baseline characteristics (age at surgery, preoperative weight, STS-EACTS category, abnormal preoperative systolic ventricular function, and surgical classification). $C I$, Confidence interval; $C M$, ciliary motion; $N I P P V$, noninvasive positive pressure ventilation; $n N O$, nasal nitric oxide. 
$17 \% ; P=.048$ ) (Table 3) with an increased combined infection incidence compared with those with normal nNO $(46 \%$ vs $17 \% ; P=.01)$ (Table 3$)$. Because viral infections were seen only in patients with abnormal CM, this precluded the ability to calculate an odds ratio. Those with low nNO had nearly 5 times the odds of acquiring an infection $(95 \%$ confidence interval, $1.42-17 ; P=.014)$ in the multivariate analysis, controlling for baseline characteristics (Table 4). The overall rate of fungal infections, bacterial pneumonia, and tracheitis was not different with abnormal CM or low nNO (Tables E5 and E6).

\section{DISCUSSION}

We found a high prevalence of abnormal airway $\mathrm{CM}$ and low nNO in non-HTX CHD infants undergoing cardiac surgery. Postoperative morbidity was significantly increased with abnormal $\mathrm{CM}$ or low nNO, with the postoperative parameters affected by abnormal $\mathrm{CM}$ differing from those affected by low nNO. Despite CM assessment and nNO measurement being standard, validated tests for PCD, the mechanism linking the 2 are unknown, and there are reports of normal nNO levels in confirmed PCD patients. ${ }^{16-18}$ Hence, the divergence in our $\mathrm{CM}$ and $\mathrm{nNO}$ findings in CHD patients is not entirely surprising.

\section{Abnormal CM Correlated With Increased Respiratory Morbidity in Non-HTX CHD Infants}

We showed non-HTX CHD infants with abnormal CM exhibited a significant increase in respiratory morbidity, including increased length of NIPPV, greater need for respiratory medications, and increased incidence of viral respiratory infections. These findings were observed despite abnormal CM infants being older at the time of surgery and more likely to have a biventricular repair, both of which have been associated with decreased postoperative morbidity/mortality. ${ }^{19,20}$

Despite not sharing classic features of PCD, CHD infants with abnormal respiratory $\mathrm{CM}$ appear to have mucociliary clearance defects that may account for their increased postoperative respiratory morbidity. This is suggested by increased use of respiratory medications, including $\beta$-agonists and inhaled corticosteroids, and the need for NIPPV. We plan to corroborate this finding in the future with direct assessments of mucociliary clearance in CHD infants with abnormal CM.

Our present study supports the previous work of Harden and colleagues, ${ }^{7}$ which showed increased postoperative use of inhaled $\beta$-agonists in HTX infants with CD. The replication of this finding in our cohort of exclusively non-HTX CHD infants at an independent institution suggests abnormal CM has broader relevance for postsurgical outcomes in infants with critical CHD, irrespective of the presence of concomitant HTX.

\section{Association of Abnormal CM Versus Low nNO With Infections}

The increased incidence of bacterial infections in infants with low nNO is consistent with the known inhibitory effect of NO on microbial growth and its modulation of the immune/inflammatory response..$^{21,22} \mathrm{NO}$ is also known to stimulate ciliary beat frequency, suggesting low $\mathrm{nNO}$ might compromise mucociliary clearance function in the airway. In contrast, we found infants with abnormal CM had increased respiratory viral infections but not bacterial infections. This may reflect a propensity for viral entry via the ciliated epithelia, observations suggesting the cilium may be the point of viral entry. ${ }^{23-26}$ Yet another study showed FUZ, a protein required for ciliogenesis, is also required for endocytosis-mediated viral entry. ${ }^{25}$

\section{Low nNO Associated With Hemodynamic Alterations}

Infants with low $\mathrm{nNO}$ exhibited a greater incidence of decreased systolic function immediately before surgery and at the time of hospital discharge. The low nNO preceded the decrease in systolic function, as the majority of infants exhibited normal systolic function at the time of nNO assessment, but their systolic function worsened by the time of surgery (median 8 days later). Abnormal systolic function in most of these infants persisted to the time of hospital discharge. Such infants also showed an increased need for intravenous supportive therapy and longer stay in the CICU. Interestingly, there was also a significant increase in use of systemic vasodilators in these infants. This finding raises the interesting possibility that defective vasoregulation may arise secondary to impaired endogenous NO production in such infants.

The alterations in hemodynamics seen in infants with low $\mathrm{nNO}$ are consistent with those reported by Yau and colleagues, ${ }^{27}$ showing low nNO levels correlated with failing single-ventricle physiology and a trend toward adverse outcomes in CHD infants with single-ventricle lesions. The benefits of adequate NO bioavailability have been further illustrated by James and colleagues, ${ }^{28}$ who showed a reduced incidence of postcardiopulmonary bypass low cardiac output syndrome in children who received supplemental NO via the bypass oxygenator during surgery. The mechanism driving the hemodynamic effects associated with low nNO is presently unknown. As cilia are thought to play a role in NO production and nonmotile primary cilia have been shown to mediate calcium signaling and mechanosensory signal transduction, CHD infants with normal motile cilia function may nevertheless have primary cilia defects that may contribute to abnormal hemodynamic regulation. ${ }^{29,30}$ Further studies are needed to investigate whether low nNO may be correlated with low systemic plasma NO species. Such studies will be needed to 
elucidate the precise link between low $\mathrm{nNO}$ and reduction in systolic function.

\section{Limitations}

A limitation in our study is the relatively small sample size of infants, which may have underestimated or failed to detect differences in certain outcome parameters. Our results are based on an observation study of 63 non-HTX CHD infants; thus, the findings from comparisons of multiple outcomes are hypothesis generating and require validation in a larger cohort. It was particularly underpowered to detect a difference in outcome for infants with both abnormal CM and low nNO, or a mortality difference, given the very low mortality rate in our study population. Reciliation data were not available for all of the patients included in our study, and thus abnormal CM may have been somewhat overestimated. This may have biased our results toward the null hypothesis for outcome parameters that are more modestly affected by abnormal CM.

\section{CONCLUSIONS}

Non-HTX CHD infants with abnormal CM showed increased postoperative morbidity, with abnormalities in $\mathrm{CM}$ predictive of poor respiratory function. Those with low $\mathrm{nNO}$ were observed to exhibit hemodynamic perturbation. Longitudinal assessment is needed to examine more long-term outcomes of surgical palliation beyond the hospital admission period for the index surgical event. Further studies also are needed to investigate the mechanisms by which abnormal $\mathrm{CM}$ and low nNO drive the different outcome parameters. Together, these findings suggest preoperative evaluation for CD in CHD infants may identify at-risk infants, thereby providing opportunities for perioperative interventions to reduce postoperative morbidity. This could improve outcomes for infants with critical CHD, many of whom must undergo multiple high-risk cardiac surgeries for palliation of their structural heart disease.

\section{Conflict of Interest Statement}

Authors have nothing to disclose with regard to commercial support.

We thank Evonne Morell (Krushansky), DO, Brian Feingold, MD, Ricardo Munoz, MD, William Devine, BS, and Linda Leatherbury, MD, for their insightful discussions in their fields of expertise.

\section{References}

1. Bush A, Hogg C. Primary ciliary dyskinesia: recent advances in epidemiology, diagnosis, management and relationship with the expanding spectrum of ciliopathy. Expert Rev Respir Med. 2012;6:663-82.

2. Shinohara K, Kawasumi A, Takamatsu A, Yoshiba S, Botilde Y, Motoyama N, et al. Two rotating cilia in the node cavity are sufficient to break left-right symmetry in the mouse embryo. Nat Commun. 2012:3:622.

3. Tan SY, Rosenthal J, Zhao XQ, Francis RJ, Chatterjee B, Sabol SL, et al. Heterotaxy and complex structural heart defects in a mutant mouse model of primary ciliary dyskinesia. J Clin Invest. 2007;117:3742-52.
4. Li Y, Klena NT, Gabriel GC, Liu X, Kim AJ, Lemke K, et al. Global genetic analysis in mice unveils central role for cilia in congenital heart disease. Nature. 2015;521:520-4.

5. Swisher M, Jonas R, Tian X, Lee ES, Lo CW, Leatherbury L. Increased postoperative and respiratory complications in patients with congenital heart disease associated with heterotaxy. J Thorac Cardiovasc Surg. 2011;141: 637-44. 644.e1-e3.

6. Nakhleh N, Francis R, Giese RA, Tian X, Li Y, Zariwala MA, et al. High prevalence of respiratory ciliary dysfunction in congenital heart disease patients with heterotaxy. Circulation. 2012;125:2232-42.

7. Harden B, Tian X, Giese R, Nakhleh N, Kureshi S, Francis R, et al. Increased postoperative respiratory complications in heterotaxy congenital heart disease patients with respiratory ciliary dysfunction. J Thorac Cardiovasc Surg. 2014; 147:1291-8.e2

8. Leigh MW, Ferkol TW, Davis SD, Lee HS, Rosenfeld M, Dell SD, et al. Clinical features and associated likelihood of primary ciliary dyskinesia in children and adolescents. Ann Am Thorac Soc. 2016;13:1305-13.

9. Garrod AS, Zahid M, Tian X, Francis RJ, Khalifa O, Devine W, et al. Airway ciliary dysfunction and sinopulmonary symptoms in patients with congenital heart disease. Ann Am Thorac Soc. 2014;11:1426-32.

10. American Thoracic Society; European Respiratory Society. ATS/ERS recommendations for standardized procedures for the online and offline measurement of exhaled lower respiratory nitric oxide and nasal nitric oxide, 2005. Am J Respir Crit Care Med. 2005;171:912-30.

11. Beydon N, Chambellan A, Alberti C, de Blic J, Clément A, Escudier E, et al. Technical and practical issues for tidal breathing measurements of nasal nitric oxide in children. Pediatr Pulmonol. 2015;50:1374-82.

12. Adams PS, Tian X, Zahid M, Khalifa O, Leatherbury L, Lo CW. Establishing normative nasal nitric oxide values in infants. Respir Med. 2015; 109:1126-30

13. O'Brien SM, Clarke DR, Jacobs JP, Jacobs ML, Lacour-Gayet FG, Pizarro C, et al. An empirically based tool for analyzing mortality associated with congenital heart surgery. J Thorac Cardiovasc Surg. 2009; 138:1139-53.

14. Lacour-Gayet F, Clarke D, Jacobs J, Gaynor W, Hamilton L, Jacobs M, et al. The Aristotle score for congenital heart surgery. Semin Thorac Cardiovasc Surg Pediatr Card Surg Annu. 2004;7:185-91.

15. Jenkins KJ, Gauvreau K, Newburger JW, Spray TL, Moller JH, Iezzoni LI. Consensus-based method for risk adjustment for surgery for congenital heart disease. J Thorac Cardiovasc Surg. 2002;123:110-8.

16. Marthin JK, Nielsen KG. Choice of nasal nitric oxide technique as first-line test for primary ciliary dyskinesia. Eur Respir J. 2011;37:559-65.

17. Karadag B, James AJ, Gültekin E, Wilson NM, Bush A. Nasal and lower airway level of nitric oxide in children with primary ciliary dyskinesia. Eur Respir J. 1999;13:1402-5.

18. Leigh MW, Hazucha MJ, Chawla KK, Baker BR, Shapiro AJ, Brown DE, et al. Standardizing nasal nitric oxide measurement as a test for primary ciliary dyskinesia. Ann Am Thorac Soc. 2013;10:574-81.

19. Anderson AW, Smith PB, Corey KM, Hill KD, Zimmerman KO, Clark RH, et al Clinical outcomes in very low birth weight infants with major congenital heart defects. Early Hum Dev. 2014;90:791-5.

20. Natarajan G, Anne SR, Aggarwal S. Outcomes of congenital heart disease in late preterm infants: double jeopardy? Acta Paediatr. 2011;100:1104-7.

21. Bogdan C. Nitric oxide and the immune response. Nat Immunol. 2001;2:907-16.

22. Uehara EU, Shida Bde S, de Brito CA. Role of nitric oxide in immune responses against viruses: beyond microbicidal activity. Inflamm Res. 2015;64: $845-52$.

23. Sims AC, Baric RS, Yount B, Burkett SE, Collins PL, Pickles RJ. Severe acute respiratory syndrome coronavirus infection of human ciliated airway epithelia: role of ciliated cells in viral spread in the conducting airways of the lungs. $J$ Virol. 2005;79:15511-24.

24. Zhang L, Peeples ME, Boucher RC, Collins PL, Pickles RJ. Respiratory syncytial virus infection of human airway epithelial cells is polarized, specific to ciliated cells, and without obvious cytopathology. J Virol. 2002;76: 5654-66.

25. Zhang L, Bukreyev A, Thompson CI, Watson B, Peeples ME, Collins PL, et al. Infection of ciliated cells by human parainfluenza virus type 3 in an in vitro model of human airway epithelium. J Virol. 2005;79:1113-24.

26. Ooi YS, Stiles KM, Liu CY, Taylor GM, Kielian M. Genome-wide RNAi screen identifies novel host proteins required for alphavirus entry. PLoS Pathog. 2013;9: e1003835. 
27. Yau C, Zahid M, Khalifa O, Devine W, Leatherbury L, Wearden P, et al. Low nasal nitric oxide as a prognosticator of failing single ventricle physiology in congenital heart disease patients. Circulation. 2014;130(suppl 2):A16375.

28. James C, Millar J, Horton S, Brizard C, Molesworth C, Butt W. Nitric oxide administration during paediatric cardiopulmonary bypass: a randomised controlled trial. Intensive Care Med. 2016;42:1744-52.

29. Nauli SM, Kawanabe Y, Kaminski JJ, Pearce WJ, Ingber DE, Zhou J. Endothelial cilia are fluid shear sensors that regulate calcium signaling and nitric oxide production through polycystin-1. Circulation. 2008;117:1161-71.
30. AbouAlaiwi WA, Takahashi M, Mell BR, Jones TJ, Ratnam S, Kolb RJ, et al Ciliary polycystin-2 is a mechanosensitive calcium channel involved in nitric oxide signaling cascades. Circ Res. 2009;104:860-9.

Key Words: nitric oxide, congenital heart disease, postsurgical outcome, airway epithelia, respiratory cilia, primary ciliary dyskinesia

Readers who found these articles interesting may also like to read the following papers found in recent and future issues of our sister publications, Seminars in Thoracic and Cardiovascular Surgery and Operative Techniques in Thoracic and Cardiovascular Surgery!

\section{Congenital: Perioperative Management}

STATE OF THE ART: Corrected Article: Surgical Techniques for Repair of Peripheral Pulmonary Artery Stenosis. Richard D. Mainwaring. Semin Thoracic Surg 2017: 198-205.

ORIGINAL SUBMISSION: Comparison of Del Nido and St Thomas Cardioplegia Solutions in Pediatric Patients: A Prospective Randomized Clinical Trial. Sachin Talwar. Semin Thoracic Surg 2017: In press.

Editorial Commentary: Who Makes the Best Martini? Jonathan M. Chen. Semin Thoracic Surg 2017: In press.

ORIGINAL SUBMISSION: Right Ventricular Outflow Reconstruction Using a Polytetrafluoroethylene Conduit with Bulging Sinuses and Tricuspid Fan-Shaped Polytetrafluoroethylene Valve. Masaaki Yamagishi. Oper Tech Thorac Cardiovasc 2016: 211-229. 


\section{APPENDIX 1. SUPPLEMENTAL METHODS AND RESULTS}

Nasal epithelial tissue samples were obtained using RhinoProbe curettage of the inferior nasal turbinate. High-speed videomicroscopy was performed and the tissue placed in culture. Upon culture, nasal epithelial cells lose their cilia, dedifferentiate, and undergo mitoses, whereupon they were grown to confluence. After confluence was achieved, cells were placed in suspension culture, allowed to reciliate, and videomicroscopy performed on the reciliated tissue. Ciliary motion (CM) of both the initial nasal scrape as well as reciliated tissue was evaluated by a panel of 3 investigators (C.W.L., M.Z., and O.K.) who were blinded to the patient phenotype and nasal nitric oxide values. Five to fifteen videos were reviewed for each sample/subject and CM classified as 1 , normal; 2 , probably normal; 3 , probably abnormal; or 4 , abnormal by consensus evaluation. To create a binary variable, those with scores of 1 or 2 were categorized as normal CM, and those with 3 or 4 were categorized as abnormal CM. Samples were not obtained on patients with evidence of ongoing respiratory disease. Whenever reciliation was possible, final determination of
CM was made based on findings from reciliated epithelial tissue, to exclude secondary (environmental, medication) causes of abnormal CM. Twenty-seven $(43 \%)$ of 63 patients had successful reciliation of nasal epithelial cells. Three $(11 \%)$ patients had a change in the classification of their ciliary motion after reciliation was performed.

Most patients underwent genetic evaluation with a comparative genomic hybridization + single-nucleotide polymorphism microarray ${ }^{\mathrm{E} 1}$ (constructed by the International Standards for Cytogenomic Arrays), which was performed at the Pittsburgh Cytogenetics Laboratory at Magee-Women's Hospital of University of Pittsburgh Medical Center. In patients with suspected genetic syndromes in whom a microarray was normal, a genetics consultation was obtained to determine the need for additional genetic testing. In $8 \%(5 / 63)$ patients, no genetic testing was available for review.

\section{E-Reference}

E1. Yatsenko SA, Davis S, Hendrix NW, Surti U, Emery S, Canavan T, et al. Application of chromosomal microarray in the evaluation of abnormal prenatal findings. Clin Genet. 2013;84:47-54. 
TABLE E1. Clinical characteristics of recruited non-HTX CHD patients

\begin{tabular}{|c|c|c|c|}
\hline ID \# & Anatomic description & Comorbidities* & Genetics \\
\hline 7004 & $\begin{array}{l}\text { DILV, d-TGA, type A interrupted } \\
\text { aortic arch }\end{array}$ & Bronchomalacia, seizures & Normal microarray \\
\hline 7027 & d-TGA & Situs inversus totalis, seizures & Normal microarray \\
\hline 7035 & ASD, VSD & Tethered cord, hypothyroidism & $\begin{array}{l}\text { Multiple congenital anomalies with } \\
\text { normal microarray }\end{array}$ \\
\hline 7040 & ASD, VSD & Bilateral grade I vesicoureteral reflux & Normal microarray \\
\hline 7042 & HLHS & & Normal microarray \\
\hline 7053 & d-TGA & & Normal microarray \\
\hline 7057 & d-TGA & & Normal microarray \\
\hline 7058 & ToF & $\begin{array}{l}\text { Tethered cord, exotropia, neurogenic } \\
\text { bladder, hydroureter }\end{array}$ & $8 \mathrm{p}$ deletion, $13 \mathrm{q} 12.11$ duplication \\
\hline 7059 & Variant AVSD & & Normal microarray \\
\hline 7102 & ToF-PA, MAPCAs & Hypocalcemia & Normal microarray \\
\hline 7113 & DORV, partial AVSD & & Normal microarray \\
\hline 7129 & d-TGA & & Normal microarray \\
\hline 7130 & $\begin{array}{l}\text { DOLV, malaligned VSD, aortic arch } \\
\text { hypoplasia }\end{array}$ & & Normal microarray \\
\hline 7134 & DORV, subaortic VSD & Aspiration, laryngeal cleft & 22q11 deletion (DiGeorge) \\
\hline 7146 & HLHS & Developmental dysplasia of hips & 1q.21 duplication \\
\hline 7151 & d-TGA & Atopic dermatitis & Normal microarray \\
\hline 7168 & DILV, 1-TGA, coarctation & & $3 \mathrm{p} 24.3$ deletion \\
\hline 7190 & ToF & & Normal microarray \\
\hline 7199 & HLHS & Hypothyroidism & 20p11.21 duplication \\
\hline 7208 & d-TGA & Duplicated renal collecting system & Normal microarray \\
\hline 7225 & HLHS & Hypothyroidism & Normal microarray \\
\hline 7242 & Truncus arteriosus & & 18p11.32 duplication \\
\hline 7253 & Coarctation, VSD & & No testing available \\
\hline 7266 & Truncus arteriosus & & No testing available \\
\hline 7281 & d-TGA & & 10q21.3q22.1 deletion \\
\hline 7288 & Truncus arteriosus & Hydronephrosis & Normal microarray \\
\hline 7295 & d-TGA & & No testing available \\
\hline 7302 & HLHS & & Normal microarray \\
\hline 7306 & d-TGA & Ectopic kidney & Normal microarray \\
\hline 7319 & DORV, subaortic VSD & Ectopic kidney & $6 \mathrm{p} 25.1 \mathrm{p} 24.3$ duplication \\
\hline 7336 & d-TGA & & Normal microarray \\
\hline 7351 & HLHS & Bilateral renal dysplasia & 16p13.3 deletion (Kabuki) \\
\hline 7374 & TA, 1-TGA & Supraventricular tachycardia & Normal microarray \\
\hline 7376 & Truncus arteriosus & Micrognathia, subglottic stenosis & 22q11 deletion (DiGeorge) \\
\hline 7379 & ToF-absent pulmonary valve & & Normal microarray \\
\hline 7380 & Critical aortic stenosis & & Normal microarray \\
\hline 7381 & d-TGA & & Normal microarray \\
\hline 7386 & HLHS & & Normal microarray \\
\hline 7389 & HLHS & & Normal microarray \\
\hline 7397 & ToF-PA & & Normal microarray \\
\hline 7400 & HLHS & & Normal microarray \\
\hline
\end{tabular}


TABLE E1. Continued

\begin{tabular}{|c|c|c|c|}
\hline ID \# & Anatomic description & Comorbidities* & Genetics \\
\hline 7401 & DORV, d-TGA & & Normal microarray \\
\hline 7405 & Infradiaphragmatic TAPVR & & Normal microarray \\
\hline 7409 & TA, d-TGA, aortic arch hypoplasia & Laryngomalacia & No testing available \\
\hline 7411 & Aortic arch hypoplasia & Intrauterine growth restriction & Normal microarray \\
\hline 7414 & Aortic arch hypoplasia, partial AVSD & & Normal microarray \\
\hline 7415 & ToF-PA & & Normal microarray \\
\hline 7421 & ToF & & Normal microarray \\
\hline 7422 & d-TGA & & Normal microarray \\
\hline 7425 & Shone complex & & Normal microarray \\
\hline 7428 & Shone complex & Supraventricular tachycardia & Normal microarray \\
\hline 7433 & d-TGA & $\begin{array}{l}\text { Prematurity, chronic lung disease, } \\
\text { grade II interventricular } \\
\text { hemorrhage }\end{array}$ & Normal microarray \\
\hline 7437 & PA-IVS & & Normal microarray \\
\hline 7438 & HLHS & Aspiration, hypospadias & Normal microarray \\
\hline 7441 & DORV, subaortic VSD & & Normal microarray \\
\hline 7444 & DILV, 1-TGA & Neuroirritability & $2 \mathrm{p} 16.3$ microdeletion (NRNX1) \\
\hline 7447 & DILV, straddling tricuspid valve & & Normal microarray \\
\hline 7448 & ALCAPA & & No testing available \\
\hline 7449 & $\begin{array}{l}\text { DORV, PA, superior-inferior } \\
\text { ventricles }\end{array}$ & Medical necrotizing enterocolitis & Normal microarray \\
\hline 7450 & TOF-PA & & \\
\hline 7458 & d-TGA & & Normal microarray \\
\hline 7459 & Shone complex & & Xp22.33q28 triplication (Triple X) \\
\hline 7466 & HLHS & Medical necrotizing enterocolitis & Normal microarray \\
\hline
\end{tabular}


TABLE E2. Demographic data for total patients and subcategorized by ciliary motion and nNO

\begin{tabular}{|c|c|c|c|c|c|}
\hline & \multirow[b]{2}{*}{ All patients $(n=63)$} & \multicolumn{2}{|c|}{ Ciliary motion $(n=59$ patients $)$} & \multicolumn{2}{|c|}{ nNO (n = 56 patients $)$} \\
\hline & & Normal $(n=40)$ & Abnormal $(n=19)$ & Normal $(n=34)$ & Low $(n=22)$ \\
\hline \multirow[t]{2}{*}{ Age at recruitment, $\mathrm{d}$} & $10(3-29)$ & $9(3-26)$ & $7(4-55)$ & $5(3-21)$ & $24(6-53)$ \\
\hline & & \multicolumn{2}{|c|}{$P=.42$} & \multicolumn{2}{|c|}{$P=.038$} \\
\hline \multirow[t]{2}{*}{ Male sex, $\mathrm{n}(\%)$} & $42(67)$ & $27(68)$ & $15(79)$ & $26(76)$ & $13(59)$ \\
\hline & & \multicolumn{2}{|c|}{$P=.55$} & \multicolumn{2}{|c|}{$P=.28$} \\
\hline \multirow[t]{2}{*}{ White race, $\mathrm{n}(\%)$} & $55(87)$ & $36(90)$ & $15(79)$ & $30(88)$ & $20(91)$ \\
\hline & & \multicolumn{2}{|c|}{$P=.42 *$} & \multicolumn{2}{|c|}{$P>.99^{*}$} \\
\hline \multirow[t]{2}{*}{ Gestation $>37$ wk, n (\%) } & $61(97)$ & $39(98)$ & $19(100)$ & $34(100)$ & $20(91)$ \\
\hline & & \multicolumn{2}{|c|}{$P>.99^{*}$} & \multicolumn{2}{|c|}{$P=.15^{*}$} \\
\hline \multirow[t]{2}{*}{ Normal genetic evaluation, $\mathrm{n}(\%)$} & $45(76)$ & $32(80)$ & $11(58)$ & $25(74)$ & $15(68)$ \\
\hline & & \multicolumn{2}{|c|}{$P=.3^{*}$} & \multicolumn{2}{|c|}{$P=.33^{*}$} \\
\hline \multirow[t]{2}{*}{ Conotruncal defects, $\mathrm{n}(\%)$} & $36(57)$ & $19(48)$ & $16(84)$ & $21(62)$ & $10(45)$ \\
\hline & & \multicolumn{2}{|c|}{$P=.010$} & \multicolumn{2}{|c|}{$P=.36$} \\
\hline
\end{tabular}

$P$ values obtained by Wilcoxon rank-sum test for continuous variables or Pearson $\chi^{2}$ test for categorical variables. $n N O$, Nasal nitric oxide. $* P$ value determined by the Fisher exact test. 
TABLE E3. CM and nNO values in recruited CHD patients

\begin{tabular}{|c|c|c|c|c|}
\hline ID \# & Initial CM & Reciliation CM & Final CM & $\mathrm{nNO}, \mathrm{nL} / \mathrm{min}$ \\
\hline 7004 & Abnormal & & Abnormal & 1.2 \\
\hline 7027 & Abnormal & & Abnormal & Not available \\
\hline 7035 & Not available & & Not available & 1.6 \\
\hline 7040 & Normal & & Normal & 1.6 \\
\hline 7042 & Abnormal & & Abnormal & Not available \\
\hline 7053 & Normal & & Normal & 1.9 \\
\hline 7057 & Not available & & Not available & 5.6 \\
\hline 7058 & Abnormal & & Abnormal & 62.8 \\
\hline 7059 & Not available & & Not available & 118.8 \\
\hline 7102 & Abnormal & & Abnormal & 87.6 \\
\hline 7113 & Abnormal & Abnormal & Abnormal & 28.1 \\
\hline 7129 & Normal & Normal & Normal & Not available \\
\hline 7130 & Normal & & Normal & Not available \\
\hline 7134 & Abnormal & & Abnormal & Not available \\
\hline 7146 & Normal & Normal & Normal & Not available \\
\hline 7151 & Normal & Abnormal & Abnormal & Not available \\
\hline 7168 & Normal & Normal & Normal & 10.4 \\
\hline 7190 & Normal & & Normal & 10.3 \\
\hline 7199 & Normal & & Normal & 10.3 \\
\hline 7208 & Abnormal & & Abnormal & 9.4 \\
\hline 7225 & Normal & Normal & Normal & 18.5 \\
\hline 7242 & Abnormal & & Abnormal & 16.1 \\
\hline 7253 & Abnormal & & Abnormal & 11.0 \\
\hline 7266 & Abnormal & Normal & Normal & 17.4 \\
\hline 7281 & Abnormal & & Abnormal & 9.6 \\
\hline 7288 & Abnormal & & Abnormal & 14.6 \\
\hline 7295 & Abnormal & Abnormal & Abnormal & 11.2 \\
\hline 7302 & Normal & & Normal & 5.8 \\
\hline 7306 & Abnormal & & Abnormal & 4.6 \\
\hline 7319 & Abnormal & & Abnormal & 16.7 \\
\hline 7336 & Normal & Normal & Normal & 20.0 \\
\hline 7351 & Abnormal & Normal & Normal & 4.6 \\
\hline 7374 & Normal & Not yet scored & Normal & 13.4 \\
\hline 7376 & Normal & & Normal & 8.2 \\
\hline 7379 & Normal & & Normal & 11.3 \\
\hline 7380 & Normal & & Normal & 20.8 \\
\hline 7381 & Normal & & Normal & 12.0 \\
\hline 7386 & Normal & & Normal & 2.8 \\
\hline 7389 & Normal & & Normal & 9.7 \\
\hline 7397 & Normal & & Normal & 11.4 \\
\hline 7400 & Normal & Normal & Normal & 9.3 \\
\hline 7401 & Normal & Normal & Normal & 15.8 \\
\hline 7405 & Normal & & Normal & 29.9 \\
\hline 7409 & Abnormal & Abnormal & Abnormal & 10.2 \\
\hline
\end{tabular}

TABLE E3. Continued

\begin{tabular}{|c|c|c|c|c|}
\hline ID \# & Initial CM & Reciliation CM & Final CM & $\mathrm{nNO}, \mathrm{nL} / \mathrm{min}$ \\
\hline 7411 & Normal & Normal & Normal & 14.9 \\
\hline 7414 & Normal & Normal & Normal & 12.1 \\
\hline 7415 & Normal & Normal & Normal & 18.0 \\
\hline 7421 & Normal & & Normal & 14.6 \\
\hline 7422 & Normal & & Normal & 1.8 \\
\hline 7425 & Normal & & Normal & 16.7 \\
\hline 7428 & Abnormal & & Abnormal & 19.4 \\
\hline 7433 & Normal & Normal & Normal & 12.1 \\
\hline 7437 & Normal & & Normal & 28.7 \\
\hline 7438 & Normal & Normal & Normal & 12.2 \\
\hline 7441 & Abnormal & Abnormal & Abnormal & 22.5 \\
\hline 7444 & Normal & Normal & Normal & 18.9 \\
\hline 7447 & Normal & Normal & Normal & 12.9 \\
\hline 7448 & Not available & & Not available & 19.3 \\
\hline 7449 & Normal & & Normal & 15.1 \\
\hline 7450 & Normal & Normal & Normal & 15.3 \\
\hline 7458 & Normal & Normal & Normal & 3.5 \\
\hline 7459 & Normal & & Normal & 8.0 \\
\hline 7466 & Normal & & Normal & 20.0 \\
\hline
\end{tabular}

CM, Ciliary motion; $n N O$, nasal nitric oxide. 
TABLE E4. Postoperative medication use subcategorized by CM and nNO

\begin{tabular}{|c|c|c|c|c|}
\hline & \multicolumn{2}{|c|}{ Events with CM data $(\mathrm{n}=91)$} & \multicolumn{2}{|c|}{ Events with nNO data $(n=83)$} \\
\hline & Normal $(\mathbf{n}=\mathbf{5 8})$ & Abnormal $(n=33)$ & Normal $(n=48)$ & Low $(\mathbf{n}=35)$ \\
\hline Budesonide, n (\%) & $1(1.7)$ & $2(6.1)$ & $0(0)$ & $2(6.0)$ \\
\hline Cisatracurium, $\mathrm{n}(\%)$ & $44(75.9)$ & $22(66.7)$ & $32(66.7)$ & $27(77.1)$ \\
\hline Epinephrine, n (\%) & $55(94.8)$ & $31(93.9)$ & $45(93.8)$ & $33(94.3)$ \\
\hline Dexamethasone, $\mathrm{n}(\%)$ & $20(34.5)$ & $10(30.3)$ & $18(37.5)$ & $10(28.6)$ \\
\hline Heliox, n (\%) & $6(10.3)$ & $0(0)$ & $4(8.3)$ & $2(5.7)$ \\
\hline Hydrocortisone, $\mathrm{n}(\%)$ & $19(32.8)$ & $3(9.1)$ & $14(29.2)$ & $10(28.6)$ \\
\hline Inhaled nitric oxide, $\mathrm{n}(\%)$ & $20(34.5)$ & $4(12.1)$ & $13(27.1)$ & $10(28.6)$ \\
\hline Methylprednisolone, n (\%) & $5(8.6)$ & $1(3.0)$ & $3(6.2)$ & $3(8.6)$ \\
\hline$N$-Acetylcysteine, n (\%) & $2(3.4)$ & $4(12.1)$ & $2(4.2)$ & $1(2.9)$ \\
\hline Nitroprusside, $\mathrm{n}(\%)$ & $11(19.0)$ & $12(36.4)$ & $9(18.8)$ & $11(31.4)$ \\
\hline Racemic epinephrine, n (\%) & $8(13.8)$ & $1(3.0)$ & $4(8.3)$ & $5(14.3)$ \\
\hline Sildenafil, n (\%) & $1(1.7)$ & $1(3.0)$ & $2(4.2)$ & $0(0)$ \\
\hline Surfactant, n (\%) & $4(6.9)$ & $5(15.2)$ & $7(14.6)$ & $4(11.4)$ \\
\hline
\end{tabular}

Data are median (interquartile range) or $\mathrm{n}(\%) . C M$, Ciliary motion; $n N O$, nasal nitric oxide.

TABLE E5. Postsurgical outcomes subcategorized by CM and nNO

\begin{tabular}{|c|c|c|c|c|}
\hline & \multicolumn{2}{|c|}{ Events with CM data $(n=91)$} & \multicolumn{2}{|c|}{ Events with nNO data $(n=83)$} \\
\hline & Normal $(\mathbf{n}=\mathbf{5 8})$ & Abnormal $(n=33)$ & Normal $(n=48)$ & Low $(n=35)$ \\
\hline CICU readmission, $\mathrm{n}(\%)$ & $7(12.1)$ & $3(9.1)$ & $3(6.2)$ & $5(14.3)$ \\
\hline Chest tube, $\mathrm{d}$ & $6.5(5-9)$ & $6(4-8)$ & $6(5-8)$ & $6(4.5-9.5)$ \\
\hline Chest tube drainage, $\mathrm{mL}$ & $626(347-983)$ & $486(186-955)$ & $606(339-957)$ & $486(234-1041)$ \\
\hline Diaphragm paralysis, $\mathrm{n}(\%)$ & $0(0)$ & $2(6.1)$ & $0(37.5)$ & $2(5.7)$ \\
\hline Fungal infection, n (\%) & NA* & $\mathrm{NA}^{*}$ & $0(0)$ & $1(2.9)$ \\
\hline Intrinsic airway disease, $\mathrm{n}(\%)$ & $5(8.8)$ & $3(9.1)$ & $4(8.5)$ & $4(11.4)$ \\
\hline Nasogastric tube, $\mathrm{n}(\%) \dagger$ & $31(53.4)$ & $20(60.6)$ & $27(56.2)$ & $21(60.0)$ \\
\hline Necrotizing enterocolitis, $\mathrm{n}(\%)$ & $4(6.9)$ & $3(9.1)$ & $4(8.3)$ & $3(8.5)$ \\
\hline Pleural effusion, $\mathrm{n}(\%)$ & $15(25.9)$ & $6(18.2)$ & $10(20.8)$ & $10(28.6)$ \\
\hline Pneumonia, n (\%) & $0(0)$ & $2(6.1)$ & $0(0)$ & $0(0)$ \\
\hline Pneumothorax, n (\%) & $1(1.7)$ & $3(9.1)$ & $2(4.2)$ & $0(0)$ \\
\hline Tracheitis, n (\%) & $1(1.7)$ & $2(6.1)$ & $0(4.2)$ & $2(5.7)$ \\
\hline Tracheostomy, n (\%) & $1(1.7)$ & $0(0)$ & $0(0)$ & $1(4.5)$ \\
\hline
\end{tabular}

Data are median (interquartile range) or $\mathrm{n}(\%) . C M$, Ciliary motion; $n N O$, nasal nitric oxide; $C I C U$, cardiac intensive care unit; $N A$, not available. ${ }^{*} \mathrm{NA}=$ not available as the single fungal infection occurred in a patient who did not have a $\mathrm{CM}$ sample. $\dagger$ Need for nasogastric tube at time of hospital discharge to meet nutritional requirement. 
TABLE E6. Detailed postoperative infection data for study participants with infection

\begin{tabular}{|c|c|c|c|c|}
\hline ID\# & Surgical encounter & Infection type & Organism & Site \\
\hline 7004 & 1 & Bacterial & Enterococcus faecalis & Blood \\
\hline 7004 & 2 & Bacterial & Coagulase-negative Staphylococcus & Blood \\
\hline 7027 & 1 & Bacterial & Vancomycin-resistant Enterococcus & Urine \\
\hline 7035 & 1 & Fungal & Candida albicans & Blood \\
\hline 7040 & 1 & Bacterial & Pseudomonas aeruginosa & Urine \\
\hline 7042 & 1 & Bacterial & Stenotrophomonas maltophilia & CSF \\
\hline 7058 & 1 & Bacterial & Enterococcus faecalis & Mediastinum \\
\hline 7102 & 1 & Bacterial & Culture negative & Mediastinum \\
\hline 7113 & 1 & Bacterial & Moraxella catarrhalis & Trachea \\
\hline 7113 & 3 & Viral & Rhinovirus/enterovirus & Nares \\
\hline 7134 & 1 & Bacterial & Streptococcus pneumoniae & Blood \\
\hline 7134 & 1 & Bacterial & Proteus mirabilis & Urine \\
\hline 7134 & 1 & Viral & Rhinovirus/enterovirus & Trachea \\
\hline 7134 & 2 & Bacterial & Coagulase-negative Staphylococcus & Mediastinum \\
\hline 7134 & 2 & Viral & Respiratory syncytial virus & Nares \\
\hline 7168 & 1 & Bacterial & Coagulase-negative Staphylococcus & Blood \\
\hline 7168 & 3 & Bacterial & Coagulase-negative Staphylococcus & Mediastinum \\
\hline 7199 & 1 & Bacterial & Culture negative & Blood \\
\hline 7242 & 1 & Bacterial & Culture negative & Abdomen \\
\hline 7302 & 1 & Bacterial & Culture negative & Mediastinum \\
\hline 7319 & 1 & Bacterial & Coagulase-negative Staphylococcus & Blood \\
\hline 7351 & 2 & Bacterial & Klebsiella oxytoca & Urine \\
\hline 7376 & 2 & Bacterial & Pseudomonas aeruginosa/Klebsiella oxytoca & Trachea \\
\hline 7386 & 1 & Bacterial & Culture negative & Mediastinum \\
\hline 7389 & 1 & Bacterial & Culture negative & Abdomen \\
\hline 7401 & 1 & Bacterial & Culture negative & Mediastinum \\
\hline 7430 & 1 & Viral & Rhinovirus & Nares \\
\hline 7438 & 2 & Bacterial & Enterococcus faecalis & Blood \\
\hline 7449 & 1 & Bacterial & Culture negative & Abdomen \\
\hline 7450 & 1 & Bacterial & Culture negative & Mediastinum \\
\hline 7466 & 1 & Bacterial & Coagulase-negative Staphylococcus & Blood \\
\hline
\end{tabular}

CSF, Cerebrospinal fluid. 